$\S=-1$

\title{
Estimation of future Reference Crop Evapotranspiration Using Soft Computing Techniques
}

\author{
L. Gowri ${ }^{1}$, K. Sasireka" \\ ${ }^{1}$ Assistant Professor School of Computing, \\ ${ }^{2 *}$ Assistant Professor, School of Civil Engineering, ${ }^{1,2}$ SASTRA Deemed University, Thanjavur, Tamil Nadu \\ *Corresponding Author E-mail: ${ }^{2}$ gowri@mca.sastra.edu, ${ }^{2 *}$ sasireka@civil.sastra.edu
}

\begin{abstract}
Estimation of Evapotranspiration forms the basis for computation of irrigation requirement of crop, and also it is considered as one of the vital component of hydrological cycle. This study describes the conceptual outline and implementation to test the ability of an artificial neural network (ANN) for accurate estimation of reference evapotranspiration $\left(\mathrm{ET}_{\mathrm{o}}\right)$. There are many conventional methods like FAO modified Penman method, temperature-based and radiation-based empirical methods are used to estimate $\left(\mathrm{ET}_{\mathrm{o}}\right)$. Among the conventional methods, Thronthwaite method and Hargreaves method perform well in the selected region. An ANN network is trained to recognize patterns of the daily meteorological variables and their corresponding evapotranspiration which is estimated using FAO-modified Penman method. The advantage of using ANN technique is the network's ability to use minimum number of meteorological parameters, hence economical.
\end{abstract}

Keywords: Evapotranspiration, Artificial Neural Network (ANN), FAO-modified Penman method, Thronthwaite method, Hargreaves method.

\section{Introduction}

Evapotranspiration is a key element in redistribution of water on the earth's surface and is a chief determinant variable in hydrological cycles. The knowledge of spatial and temporal variation of evapotranspiration is essential for sustainable water resource management (Jiang and Islam, 2001). The term $\mathrm{ET}_{\mathrm{o}}$ include the total evaporation from plant and adjacent areas. It is important to irrigation management, because the crop yield relates directly to $\mathrm{ET}_{\mathrm{o}}$. Since yield increases linearly with $\mathrm{ET}_{\mathrm{o}}$, maximum yield will not be reached unless the maximum $\mathrm{ET}_{\mathrm{o}}$ level is reached. Many methods have been developed and tested for estimation of $\mathrm{ET}_{\mathrm{o}}$. FAO modified Penman method is reliable method for estimation of $\mathrm{ET}_{\mathrm{o}}$ when the required vegetation and weather data are known (Amatya et al.1995). Nowadays soft computing technique can be used as alternative method to find solution for many intricate problems because it is not necessitate knowing about internal system variables and it will give simpler solution for multivariable problems.

An ANN is widely applied in the broad range of fields, including image and signal processing, weather forecasting, water resources and environmental systems. An ANN is a biological and computation model based on the understanding of information processing system. ANNs are classified into two broad categories: feed-forward and feed-backward neural network. Both the neural networks are further classified into single layer and multi layer architecture network. ANNs are based on the current understanding of the biological nervous systems. Jothiprakash et al., (2002) stated that the ANN applied to solve the $\mathrm{ET}_{\mathrm{o}}$ problems can be very effective as well as economical. The exact value of the $\mathrm{ET}_{\mathrm{o}}$ mainly depends upon the accuracy of the training data. ANN was used for $\mathrm{ET}_{\mathrm{o}}$ calculation by many and detailed description and application can be found elsewhere (Freeman et al. 1991, Kumar et al. 2011, Shiri et al. 2014, Shahaboddin Shamshirband et al. 2016).

The main aim of this study is to forecast evapotranspiration by ANN technique and to verify the suitability of this method by comparing the $\mathrm{ET}_{\mathrm{o}}$ estimated from econventional method like FAO modified Penman method, Thronthwaite method, Hargreaves method. Eventhough FAO modified Penman method results in accurate estimation of $\mathrm{ET}_{\mathrm{o}}$, it requires lot of meteorological variables like maximum, minimum and dewpoint temperature, actual sunshine hours, relative humidity, wind speed etc., but in many places, only limited meteorological information are available for estimating $\mathrm{ET}_{\mathrm{o}}$. Hence in this study an attempt is made to predict future $\mathrm{ET}_{\mathrm{o}}$ using minimum number of available data with help of ANN technique.

\section{Study Area}

The data collected from kurungulam climatotlogical station has been used for evaluation and comparison of evapotranspiration from conventional and ANN model. This station is located in Thanjavur district in Tamil Nadu, India at a latitude of $9^{\circ} 50^{\prime} \mathrm{N}$ and longitude of $75^{\circ} 45^{\prime} \mathrm{E}$. The total annual rainfall varies from $500 \mathrm{~mm}$ to $1500 \mathrm{~mm}$ with dry period of 5 to 6 months. Several meteorological variable including air and dew point temperature, wind speed relative humidity, and sunshine hours for the period of 1990 to 2000 has been used for the estimation of $\mathrm{ET}_{\mathrm{o}}$. The monthly average of the main climatic parameter for Kurungulam station is shown in table.1. 
Table 1. Meteorological parameter for Kurungulam station

\begin{tabular}{|c|c|c|c|c|c|c|c|c|c|}
\hline \multirow{4}{*}{ Month } & \multicolumn{9}{|c|}{ Table } \\
\hline & \multirow{3}{*}{\begin{tabular}{|l} 
Maximum \\
temperature
\end{tabular}} & \multirow{3}{*}{\begin{tabular}{|l|} 
Minimum \\
temperatur
\end{tabular} \mid} & \multirow{3}{*}{$\mid \begin{array}{l}\mathrm{RH} \\
\text { Mean } \\
\%\end{array}$} & \multirow{3}{*}{$\mid \begin{array}{l}\text { Wind } \\
\text { velocity in } \\
\mathrm{km} / \mathrm{hr}\end{array}$} & \multirow{2}{*}{$\begin{array}{c}\text { Actual } \\
\text { sunshine }\end{array}$} & Dew & Max & Solar & \multirow{2}{*}{$\begin{array}{l}\text { Mean daily } \\
\% \text { of annual }\end{array}$} \\
\hline & & & & & & point & sunshine & radiation & \\
\hline & & & & & $\mathrm{N} \mathrm{hr}$ & & $\mathrm{N} \mathrm{hr}$ & $\mathrm{Ra} \mathrm{mm} / \mathrm{d}$ & daytime hrs p \\
\hline Jan & 28.13 & 19.81 & 87.46 & 4.97 & 7.32 & 20.74 & 11.60 & 13.20 & 0.26 \\
\hline Feb & 30.18 & 20.62 & 88.51 & 3.67 & 4.91 & 21.87 & 11.80 & 14.20 & 0.27 \\
\hline Mar & 32.58 & 21.66 & 84.72 & 3.73 & 9.34 & 22.73 & 12.00 & 15.30 & 0.27 \\
\hline Apr & 34.65 & 24.55 & 78.96 & 5.74 & 7.71 & 25.17 & 12.30 & 15.70 & 0.28 \\
\hline May & 35.38 & 25.82 & 75.72 & 7.73 & 7.63 & 24.89 & 12.60 & 15.50 & 0.28 \\
\hline Jun & 34.80 & 25.80 & 81.22 & 10.00 & 7.07 & 25.68 & 12.70 & 15.30 & 0.29 \\
\hline Jul & 33.88 & 25.41 & 74.22 & 9.49 & 6.37 & 23.44 & 12.60 & 15.30 & 0.29 \\
\hline Aug & 32.97 & 24.58 & 79.19 & 7.80 & 7.56 & 23.20 & 12.40 & 15.50 & 0.28 \\
\hline Sep & 32.44 & 24.29 & 81.67 & 5.52 & 8.28 & 23.26 & 12.10 & 15.30 & 0.28 \\
\hline Oct & 31.63 & 25.71 & 81.77 & 4.35 & 5.92 & 23.30 & 11.80 & 14.70 & 0.27 \\
\hline Nov & 28.62 & 22.61 & 86.77 & 4.92 & 6.55 & 22.72 & 11.60 & 13.60 & 0.26 \\
\hline Dec & 27.59 & 20.97 & 85.75 & 5.21 & 6.68 & 20.79 & 11.50 & 12.90 & 0.26 \\
\hline
\end{tabular}

In this study area, out of several temperature methods

\section{Methodology}

Daily data collected from Kurungulam station has been used to find reference crop eavopotranspiration. The FAO modified Penman method as recommended by FAO 24 (Doorenbos and Pruitt, 1977; and Mohan and Ramprasad, 1987) was taken as a standard method in evaluating the performance of ANN models and conventional methods. Thronthwaite (1948) method gave most accurate result in comparison with Modified Penman method (Jothiprakash et al. 2007) and out of several radiations based methods Hargreaves (1975) method gave most acceptable result in comparison with Modified Penman method (Jothiprakash et al. 2008). The methodology adopted for this study area is shown in Fig. 1

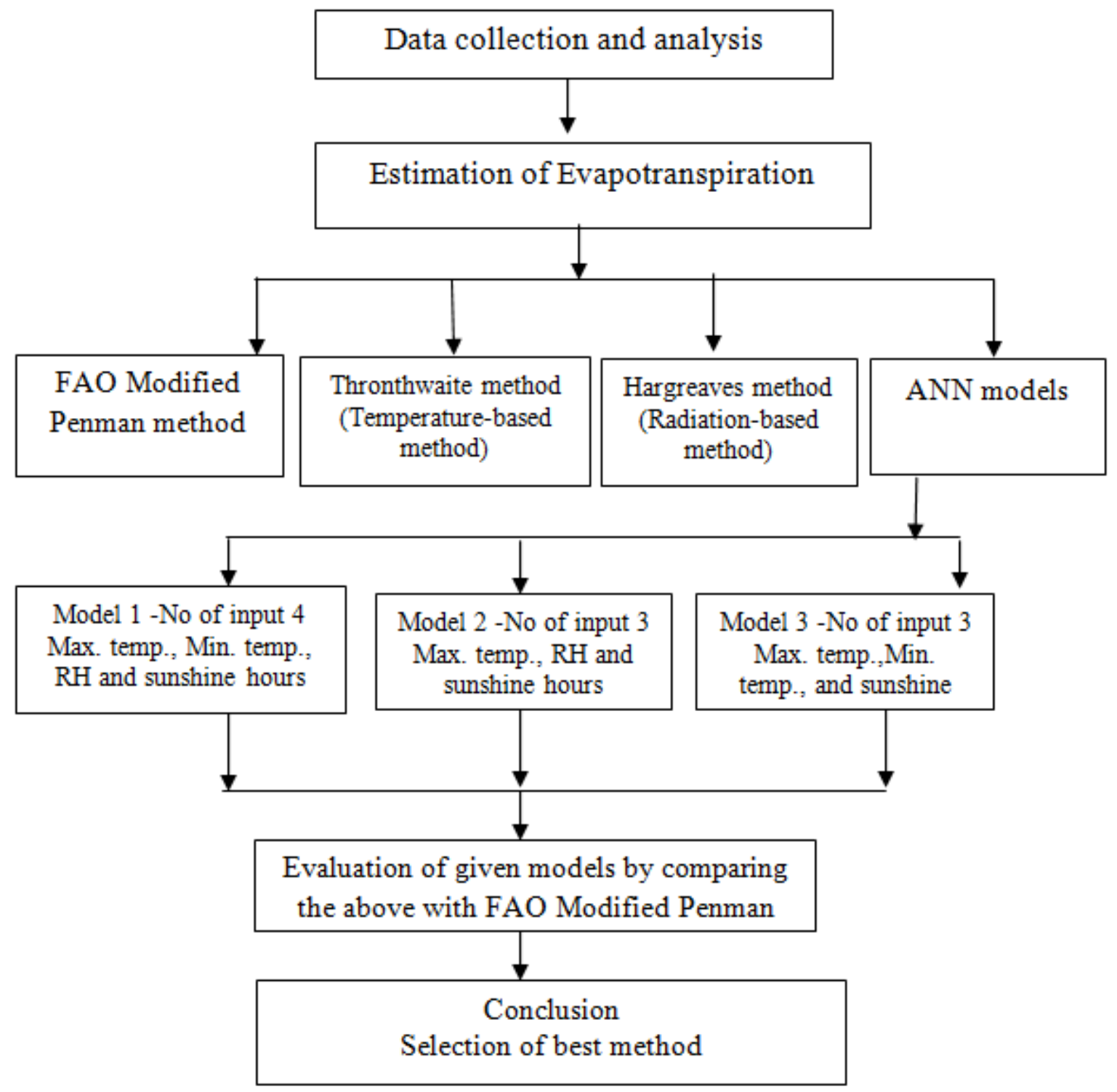

Fig. 1: Methodology adopted for present study 
In this study area, three types of ANN model has been developed namely ANN model 1, ANN model 2 and ANN model 3 and the structure of network is shown in Fig. 2 In an ANN the acquired information can be processed by mathematical simulation of biological nervous system in order to derive predictive output after training of the network for pattern recognition.

The network topography usually organized in a number of layers consists of a set of nodes and are connected by links. The input parameters namely minimum and maximum temperature, mean relative humidity and actual sunshine hours along with daily $\mathrm{ET}_{\mathrm{o}}$ estimated using FAO Modified Penman method are used to train the ANN model, which employs feed forward backpropagation technique. The backpropagation is the best technique for multilayer feed forward neural network. It supports different activation function to learn training set of input and output dataset effectively. The training objective is to alter the weights for that the set of inputs produces the predicted outputs and also errors are propagated towards backward direction in order to minimize the errors. This model trained large numbers of input and output pairs with minimum amount of time. An ANN act as best observer for recognizing the predicated output from the given set of input. To exporting the data to the ANN for training, normalization of the data must be carried out to restrict the data range. ANN was performed in Neural Network Toolbox in Matlab R2016 b. The feed forward network is used with TRINLM training function and TAnSIG transfer function to predict $\mathrm{ET}_{\mathrm{o}}$. The network comprises of an input layer and an output layer with a single hidden layer. The number of units in the hidden layer is seven. The single output layer with single unit represents the estimated daily $\mathrm{ET}_{\mathrm{o}}$ value.

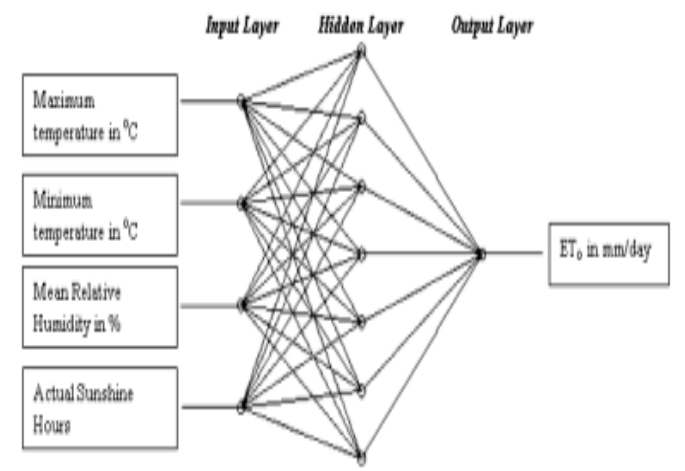

(a)

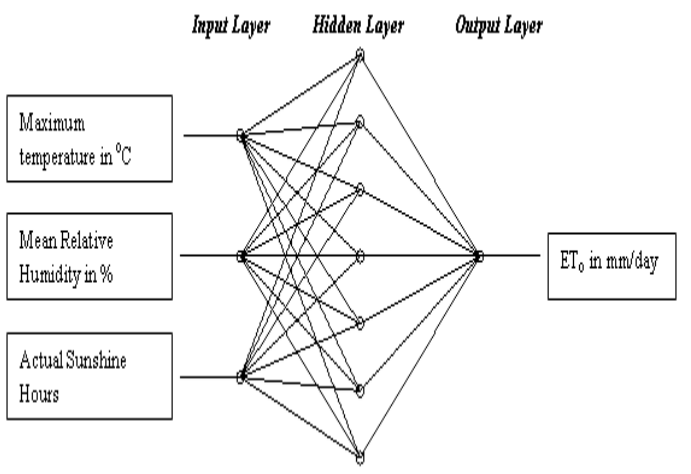

(b)

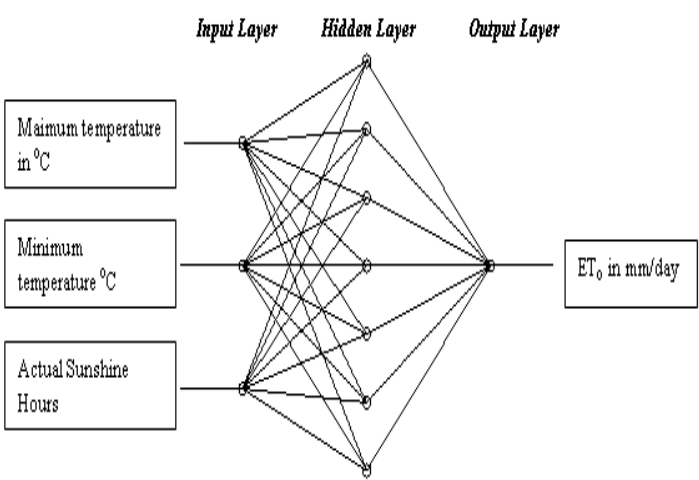

(c)

Fig. 2: Structure of ANN model for predicting the daily $\mathrm{ET}_{\mathrm{o}}$

\section{Results and Discussion}

The daily data collected from Kurungulam station for the period of 10 years has been used to calculate $\mathrm{ET}_{\mathrm{o}}$. Among 10 years daily data $75 \%$ of data has been assigned for training of ANN network, $15 \%$ used for validation and remaining $15 \%$ of the data used to predict $\mathrm{ET}_{\mathrm{o}}$ values of the selected region. Three types of ANN model were developed by varying the number of input as well as type of input variable. Regression plot of three models namely ANN model 1, ANN model 2, and ANN model 3 are shown in Figure 3, Fig. 4 and Fig. 5 respectively. In all the models, R value for Training, Validation and Testing ranges from 0.93 to 0.96 . It shows that the suitability of ANN for predicting future $\mathrm{ET}_{0}$.
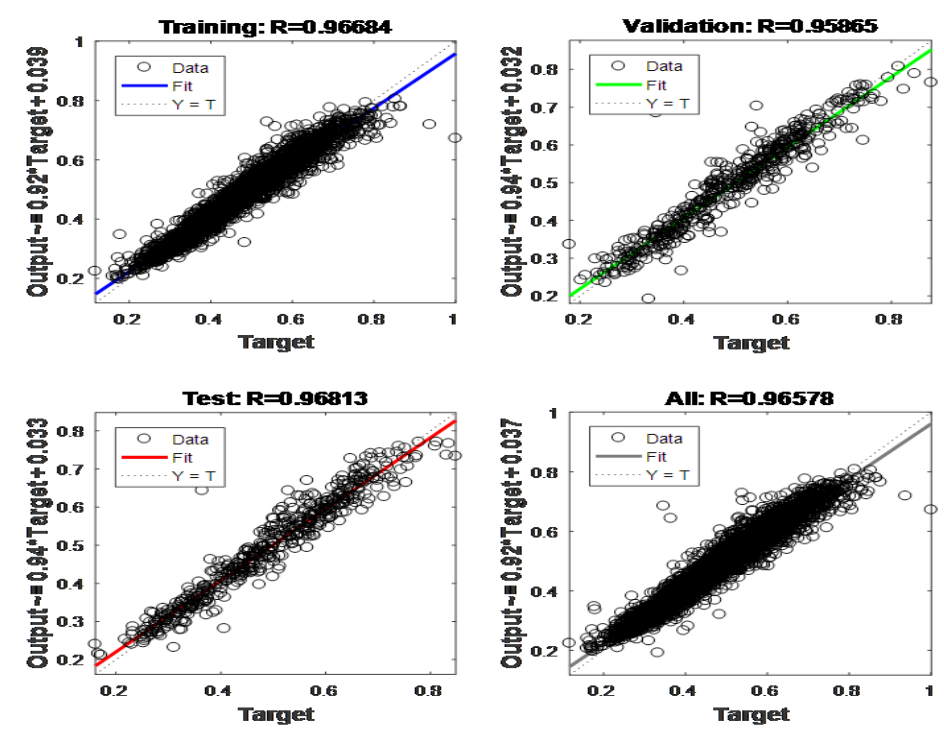

Fig. 3: Regression Plot of ANN Model 1 

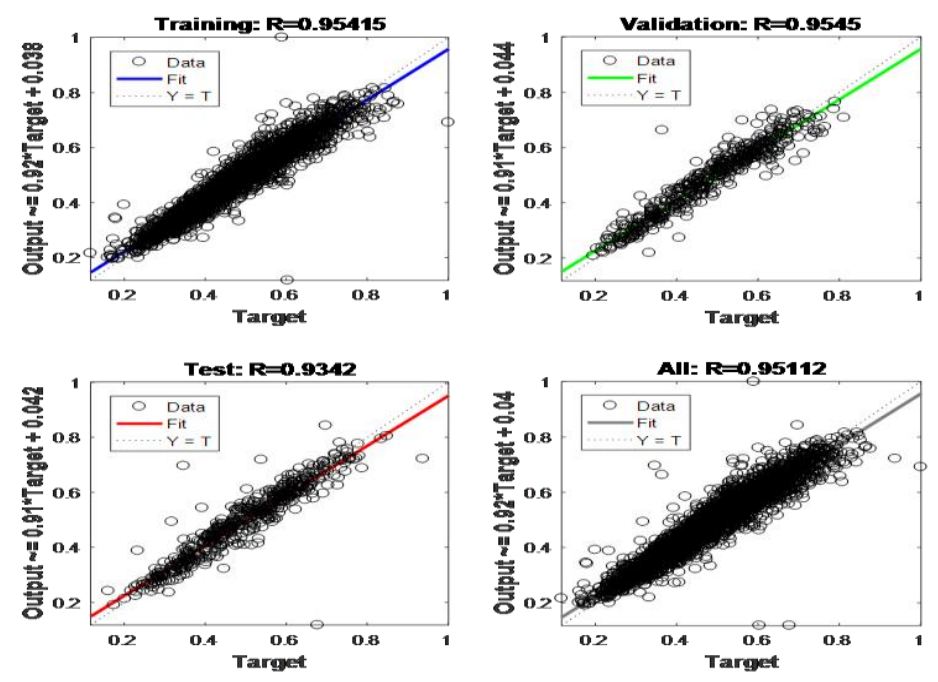

Fig. 4: Regression Plot of ANN Model 1
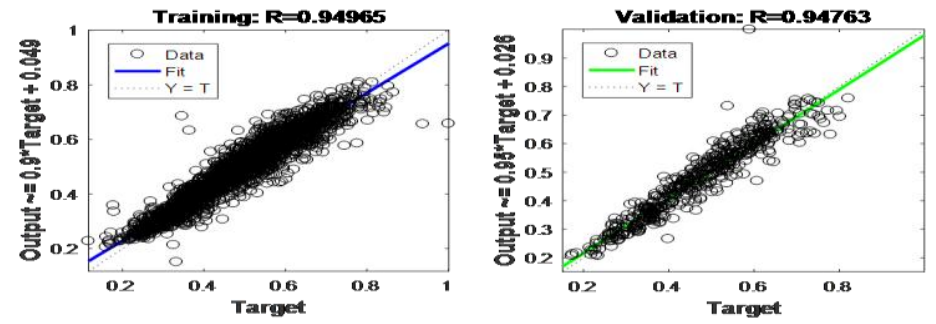

Test: $\mathbf{R}=0.95994$
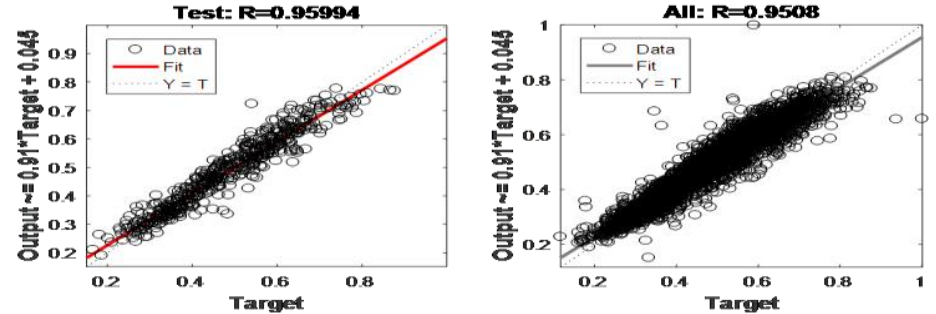

Fig. 5: Regression Plot of ANN Model 3

Percentage error $=\frac{\left(\text { ETo }(\text { Other methods })-\text { ETo }_{\text {Pen }}\right)}{\text { ETo }_{\text {Pen }}} \times 100$

(1)

Percentage of error calculated by using equation 1 is shown in table 2. Postive and Negative values implies that the overestimated and under estimated ETo value respectively compared to FAO modified Penman method. Comparing the conventional model and ANN models with FAO modified Penman method, percentage of error is minimum in all ANN models.

Table 2: Comparison of Conventional and ANN model with FAO modified Penman method

\begin{tabular}{|c|c|c|c|c|c|c|c|c|c|c|c|}
\hline Month & \begin{tabular}{|c|}
$\mathrm{ET}_{0-}$ \\
Penman \\
$(\mathrm{mm} /$ day $)$
\end{tabular} & \begin{tabular}{|c|}
$\mathrm{ET}_{\mathrm{o}_{-}}$ \\
Thronthwaite \\
(mm/day)
\end{tabular} & Error (\%) & \begin{tabular}{|c|} 
ETo_ \\
Hargreaves \\
(mm/day) \\
\end{tabular} & Error (\%) & $\begin{array}{c}\text { ETo_ANN } \\
\text { Model } 1 \\
(\mathrm{~mm} / \text { day })\end{array}$ & Error (\%) & \begin{tabular}{|c} 
ETo_ANN \\
Model 2 \\
(mm/day)
\end{tabular} & Error (\%) & $\begin{array}{c}\text { ETo_ANN } \\
\text { Model } 3 \\
\text { (mm/day) }\end{array}$ & Error (\%) \\
\hline Jan & 3.864 & 4.362 & 12.908 & 4.210 & 8.960 & 3.991 & 3.294 & 4.047 & 4.756 & 3.987 & 3.187 \\
\hline Feb & 3.699 & 4.497 & 21.580 & 3.796 & 2.647 & 3.653 & -1.231 & 3.725 & 0.710 & 3.702 & 0.083 \\
\hline Mar & 5.714 & 4.666 & -18.344 & 5.929 & 3.770 & 5.586 & -2.240 & 5.691 & -0.404 & 5.668 & -0.801 \\
\hline Apr & 5.639 & 4.944 & -12.324 & 5.660 & 0.364 & 5.681 & 0.743 & 5.699 & 1.055 & 5.732 & 1.647 \\
\hline May & 5.879 & 5.058 & -13.975 & 5.597 & -4.807 & 5.984 & 1.775 & 5.917 & 0.635 & 5.972 & 1.579 \\
\hline Jun & 5.568 & 5.004 & -10.126 & 5.237 & -5.956 & 5.590 & 0.394 & 5.535 & -0.593 & 5.621 & 0.942 \\
\hline Jul & 5.455 & 4.947 & -9.326 & 4.929 & -9.649 & 5.271 & -3.375 & 5.198 & -4.711 & 5.181 & -5.033 \\
\hline Aug & 5.636 & 4.846 & -14.021 & 5.406 & -4.069 & 5.417 & -3.883 & 5.352 & -5.043 & 5.361 & -4.875 \\
\hline Sep & 5.547 & 4.800 & -13.465 & 5.647 & 1.799 & 5.452 & -1.703 & 5.406 & -2.537 & 5.461 & -1.557 \\
\hline Oct & 4.258 & 4.784 & 12.370 & 4.571 & 7.356 & 4.307 & 1.168 & 4.261 & 0.070 & 4.336 & 1.847 \\
\hline Nov & 3.433 & 4.516 & 31.544 & 4.243 & 23.614 & 3.585 & 4.433 & 3.576 & 4.164 & 3.649 & 6.300 \\
\hline Dec & 3.641 & 4.392 & 20.630 & 3.958 & 8.706 & 3.776 & 3.715 & 3.791 & 4.114 & 3.771 & 3.561 \\
\hline
\end{tabular}

Figure 6 shows regression plot of average monthly $\mathrm{ET}_{\mathrm{o}}$ from method against FAO modified Penman method. As for as the $\mathrm{R}^{2}$ conventional methods namely Thronthwaite and Hargreaves value concerned, Thronthwaite method has lowest $\mathrm{R}^{2}$ value of 
0.725 and Hargreaves method has highest value of 0.89 . Regression analysis between $\mathrm{ET}_{\mathrm{o}}$ values estimated by standard method and ANN models are shown in Figure 7 and it shows good correlation with $\mathrm{R}^{2}$ of 0.98 . Figure 8 shows the comparison of average monthly $\mathrm{ET}_{\mathrm{o}}$ estimated by conventional and ANN models. From figure 8 it can be seen that the conventional methods shows large deviation compared to ANN models and ANN models follow the FAO modified Penman $\mathrm{ET}_{\mathrm{o}}$ for all months except July and August. Hence it can be concluded that the results predicted by ANN models with lesser input variables is applicable to the selected study area.
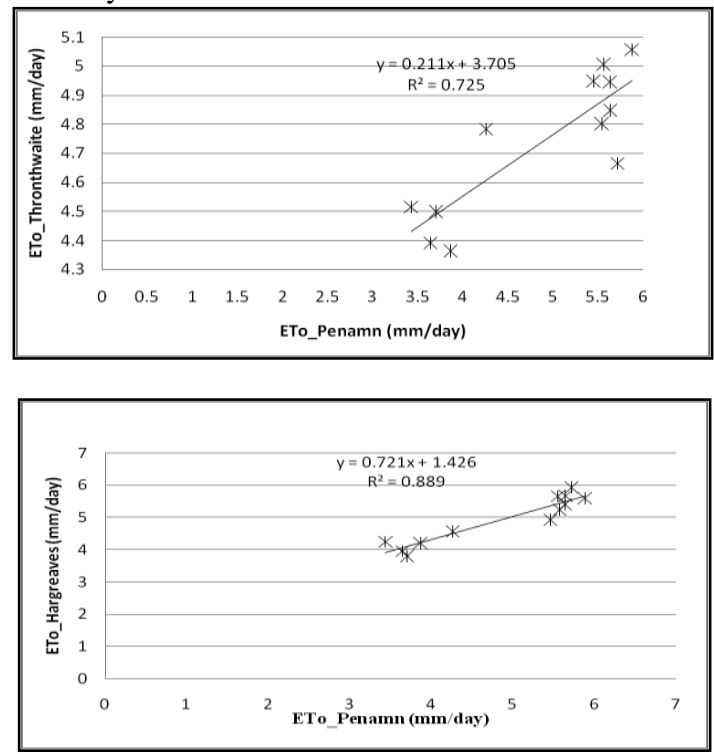

Fig. 6: Regression Plot of Average monthly $\mathrm{ET}_{\mathrm{o}}$ by conventional methods
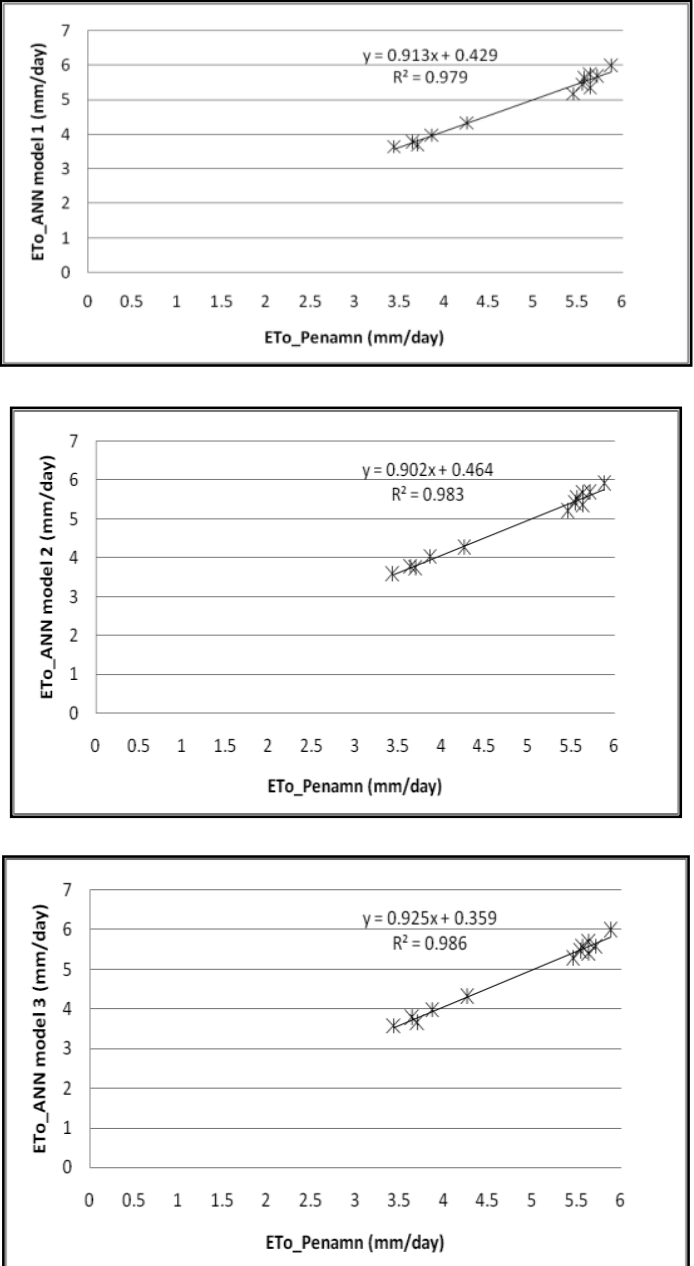

Fig. 7: Regression Plot of Average monthly $\mathrm{ET}_{\mathrm{o}}$ by ANN models

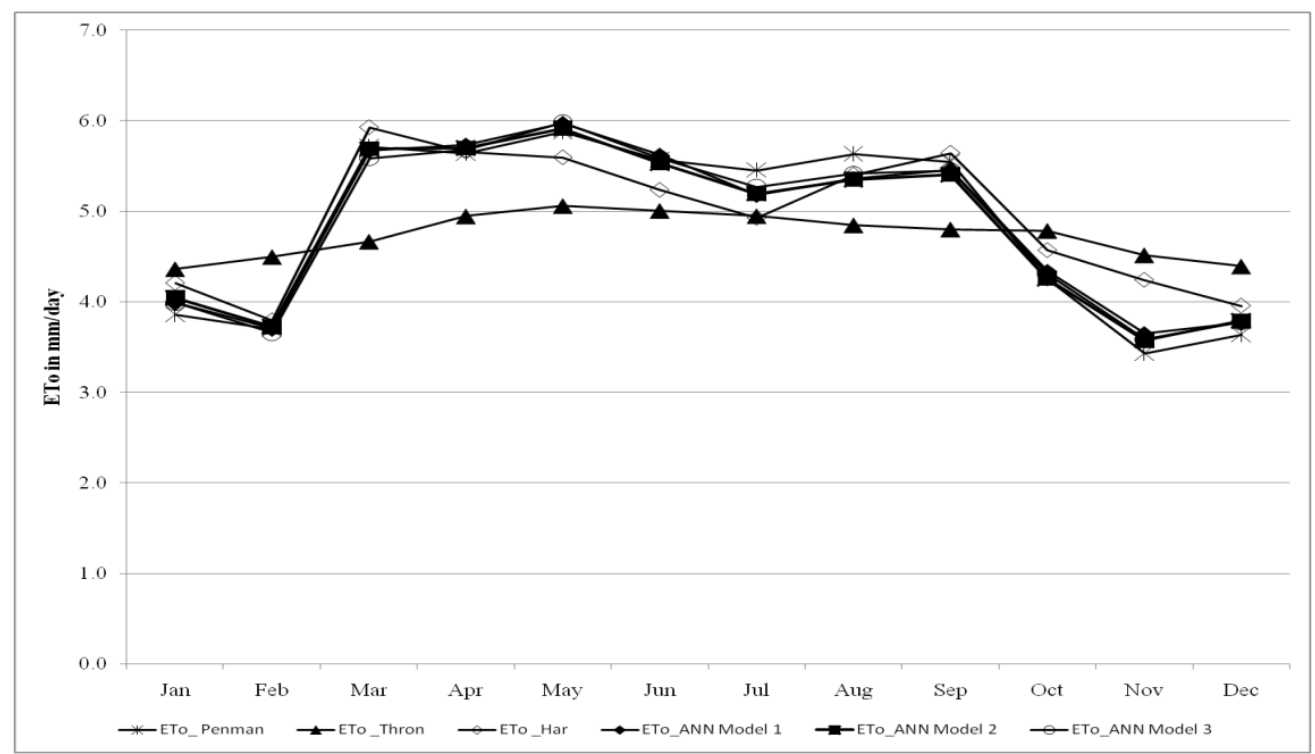

Fig.8: comparisons of average monthly $\mathrm{ET}_{\mathrm{o}}$ values by conventional methods and $\mathrm{ANN}$ models.

\section{Conclusions}

In this study, a feed forward back propagation technique has been used to model and predict reference crop evapotranspiration in Kurungualm station, Thanjavur district.

Comparing the three ANN models with conventional model shows that ANN model perform well for prediction of $\mathrm{ET}_{\mathrm{o}}$, and
Comparison among ANN models shows that ANN model 1 performed well considering $\mathrm{R}$ value and percentage of errors with FAO modified Penman method. The results of this study have showed that feed forward back propagation technique can be used as a tool to predict future $\mathrm{ET}_{\mathrm{o}}$. Future work is suggested to include a comparison of a few ANN methods by varying learning rate, training and activation function in order to obtain more accurate prediction results. 


\section{References}

[1] D. M. Amatya, R. W. Skagga, and J. D. Gregory, Journal of Irrigation and Drainage Engineering, ASCE, 121(6), 427- 435 (1995).

[2] J. Doorenbos, WO. Pruitt, Irrigation and Drainage Paper 24, Food and Agriculture Organization of the United Nations. Rome. Italy, pp. 144 (1977).

[3] J. A. Freeman, and D. M. Skapura (1991) Addison-Wesley Publishing Company, New York, (1991).

[4] G.H. Hargreaves, Transaction of the American Society of Agricultural Engineers 18, 980-984 (1975).

[5] L. Jiang, and S. Islam, Water Resour. Res 37(2): .329-340 (2001).

[6] V. Jothiprakash, MR. Ramachandran,P. Shamuganathan, Journal of Institution of Engineers (India) 18,17-20 (2002)

[7] V. Jothiprakash, M.G. Devamane, and K. Sasireka, Journal of Institution of Engineers (India), Vol, 88, Dec(AG), 19-26. ( 2007)

[8] V. Jothiprakash, M.G. Devamane, and K. Sasireka, Journal of Institution of Engineers (India) Vol. 89, Dec(AG), 22-27 (2008).

[9] M. Kumar, N. S. Raghuwanshi, and R. Singh, Irrig. Sci., 29(1), 11-25 (2011)

[10] S. Mohan, and Rama Prasad, Research Report No WRI Departmen of Civil Engineering, Indian Institute of Science, Bangalore (1987).

[11] J. Shiri, et al. Comput. Electron. Agric., 108, 230-241 (2014).

[12] Shahaboddin Shamshirband, Mohsen Amirmojahedi, Milan Goci, Shatirah Akib, Dalibor Petkovi, Jamshid Piri,; and Slavisa Trajkovic, J. Irrig. Drain Eng., 142(2): 04015044, (2016).

[13] CW. Thronthwaite, Geographical Review 38: 55-94 (1948) 